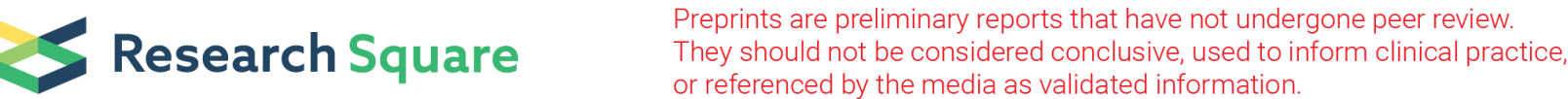

\section{Association Between Dietary Onion Intake and Subclinical Hypothyroidism in Adults: A Population- Based Study From an Lodine-Replete Area}

Juanjuan zhang

Tianjin Medical University

Yeqing Gu

Tianjin Medical University

Ge Meng

Tianjin Medical University

Qing Zhang

Tianjin Medical University First Hospital: Tianjin Medical University General Hospital

Li Liu

Tianjin Medical University First Hospital: Tianjin Medical University General Hospital

\section{Hongmei Wu}

Tianjin Medical University

Shunming Zhang

Tianjin Medical University

\section{Yawen Wang}

Tianjin Medical University

\section{Tingjing Zhang}

Tianjin Medical University

\section{Xuena Wang}

Tianjin Medical University

\section{xu zhang}

Tianjin Medical University

\section{Xing Wang}

Tianjin Medical University First Hospital: Tianjin Medical University General Hospital

Shaomei Sun

Tianjin Medical University First Hospital: Tianjin Medical University General Hospital

\section{Ming Zhou}

Tianjin Medical University First Hospital: Tianjin Medical University General Hospital

\section{Qiyu Jia}

Tianjin Medical University First Hospital: Tianjin Medical University General Hospital

\section{Kun Song}


Tianjin Medical University First Hospital: Tianjin Medical University General Hospital

\section{Kaijun Niu(Dnkj0809@gmail.com )}

Tianjin Medical University https://orcid.org/0000-0002-8772-2481

\section{Original Article}

Keywords: Diet, Onion, Subclinical Hypothyroidism, Adult Population

Posted Date: February 8th, 2021

DOl: https://doi.org/10.21203/rs.3.rs-171485/v1

License: (c) (1) This work is licensed under a Creative Commons Attribution 4.0 International License. Read Full License

Version of Record: A version of this preprint was published at Endocrine on July 31st, 2021. See the published version at https://doi.org/10.1007/s12020-021-02790-2. 


\section{Abstract}

\section{Background \& Aims}

The protective effect of onion against thyroid hypofunction has been reported in animal studies. However, in humans, the association between onion consumption and subclinical hypothyroidism are unclear. The study sought to explore the association between habitual onion intake and subclinical hypothyroidism among adult population from an iodine-replete area.

Objective

We aimed to investigate the relationship between dietary onion intake and subclinical hypothyroidism in Chinese population

Methods

A cross-sectional study (6,515 men and 5,290 women) was performed in Tianjin, China. Frequency of onion consumption was assessed using a valid self-administered food frequency questionnaire. Serum free triiodothyronine (FT3), free thyroxine (FT4), and thyroid-stimulating hormone (TSH) were determined by chemiluminescence immunoassay. Subclinical hypothyroidism was diagnosed with TSH $>4.78 \mathrm{IU} / \mathrm{mL}$. Multiple logistic regression was used to evaluate the association of onion intake with subclinical hypothyroidism.

Results

The prevalence of subclinical hypothyroidism was $2.56 \%$ in men and $7.18 \%$ in women, respectively. In women, the fully adjusted odds ratios [95\% confidence interval $(\mathrm{Cl})$ ] of having subclinical hypothyroidism across increasing frequency of onion intake were 1.00 (reference) for $<1$ time/week, 0.99 (0.74-1.34) for 1-3 times/week, 0.73 (0.53-1.01) for 4-6 times/week, and 0.66 (0.46-0.95) for $\geq 7$ times/week ( $P$ for trend $<0.01)$. However, we observed no significant association between onion intake and subclinical hypothyroidism in men. Stratified analyses suggested a potential effect modification by age; the odds ratios $(95 \% \mathrm{Cl})$ across extreme quartiles was $0.43(0.20,0.87)$ in $<40$ women and $1.05(0.49,2.28)$ in >60 women.

Conclusions

Frequent consumption of onion is inversely associated with subclinical hypothyroidism in adult women from an iodine-replete area. Further studies are needed to explore the casual relationship.

\section{Introduction}

Subclinical hypothyroidism $(\mathrm{SCH})$ is a relatively common endocrine disorder refers to thyroid hormone deficiency. Studies have reported the prevalence of hypothyroidism was between $4 \%$ and $10 \%$, and that of 
SCH was up to $10 \%$, depending on the definition used ${ }^{1,2}$. Hypothyroidism could interfere with daily life, such as dry skin, cold sensitivity, constipation, fatigue and muscle cramp, this condition also could cause some chronic diseases like heart attack, cancer, even death ${ }^{3}$. $\mathrm{SCH}$ can be seen as a mild form of thyroid failure, however, the risk of progression of $\mathrm{SCH}$ to overt hypothyroidism is approximately 2 to $6 \%$ per year ${ }^{4}$. Thus, $\mathrm{SCH}$ has become a public health problem, which deserves our high attention.

Worldwide, overt hypothyroidism is most commonly caused by environmental iodine deficiency; however, in iodine-replete regions, chronic autoimmune thyroiditis is the most common cause of thyroid hypofunction ${ }^{5}$. Although the exact mechanisms underlying autoimmune thyroiditis are unknown, studies have suggested that there is a multifactorial aetiology involving both genetic, environmental and nutritional factors ${ }^{6}$. Nutritional factors that affect thyroid function include the micronutrients iodine, iron, and selenium $(\mathrm{Se})^{7}$. These micronutrients are mainly sourced and supplemented from daily dietary intake. Daily diet is crucial in the development and prevention of thyroid disease ${ }^{8,9}$.

Onions (Alliumcepa) belong to the family Liliaceae and are widely used in many households as spices, especially in Greeks, Egyptians, Indians and Chinese ${ }^{10}$. Nowadays, onion has been widely recommended for the prevention and treatment of many diseases because it is rich in organosulfur compounds and flavanols ${ }^{11}$, which have multiple beneficial effects, including cholesterol-lowering action and antioxidant and radical scavenging effects ${ }^{12}$. Sallylcysteine (SAC), one of organosulfur compounds as an antioxidant, not only can improve serum T3 and T4 back to its normal levels ${ }^{13}$, but also can stimulate the increase of insulin secretion, thereby stimulating hepatic T4/T3 conversion and to improve the synthetic capacity of thyroid cells ${ }^{14}$. In addition, flavonols can inhibit the activities of enzymes antithyroperoxidase and liver deiodinase as the key enzyme in the biosynthesis of thyroid hormones and bring about some changes in thyroid functions ${ }^{15}$. Onions are also rich in Se, which may contribute to their regulatory effect on the thyroid ${ }^{10}$. Studies showed that Se could positively modulate the endocrineimmune system interface in autoimmune thyroid disease by disrupting self-amplifying cycles of hydrogen peroxide generation, inflammatory cytokine release and autoantibody production ${ }^{16}$. Therefore, we speculated that daily consumption of onion might have a beneficial effect on the prevention of $\mathrm{SCH}$ due to its hormone regulation capacity as well as its anti-inflammatory and antioxidant effects.

To date, few studies have assessed the relationship between consumption of onion and $\mathrm{SCH}$ in adults. Therefore, we designed a cross-sectional study to explore whether consumption of onion is related to $\mathrm{SCH}$ in a large-scale adult population.

\section{Materials And Methods}

\section{Participants}

The present study is a cross-sectional analysis of baseline data from the Tianjin Chronic Low-grade Systemic Inflammation and Health (TCLSIH) dataset, which is a large prospective dynamic cohort study 
evaluating the association between inflammation and chronic diseases among general Chinese adults living in Tianjin, China. Participants in this study had received health examinations and had completed questionnaire survey to assess diet and lifestyle factors. The survey response rate is above $93.7 \%$. The TCLSIH study design has been described in detail previously ${ }^{17}$. Exclusion criteria for participants in this study were as the followings: (1) a history of thyroid disease; (2) subclinical or overt hyperthyroidism (serum TSH $<0.55 \mathrm{mlU} / \mathrm{L}$ with elevated FT4); (3) overt hypothyroidism (serum TSH $>4.78 \mathrm{mIU} / \mathrm{L}$ with low FT4); (4) a clear history of cardiovascular disease (CVD) or cancer; (5) insufficient data. After these exclusions, a total of 11,805 participants (mean [standard deviation] age: 45.2 [11.3] years; men, 55.2\%) were included in the current analysis. The flow chart of study participants is given in Figure1. The protocol of this study was approved by the Institutional Review Board of the Tianjin Medical University and participants gave written informed consent prior to participate in the study.

\section{Assessment of dietary intake}

Dietary intake was assessed using a 100-item Food Frequency Questionnaire (FFQ). The FFQ assessed consumption frequency and portion sizes of various foods over the past month by checking one of 7 frequency categories ranging from 'almost never' to ' $\geq 2$ times/day' for foods and 8 frequency categories ranging from 'almost never' to ' $\geq 4$ times/day' for beverages (including soft drinks). The specific amount of food in the table was described by natural portions or standard weight and volume measures of the servings commonly consumed in this study population ${ }^{18}$. The mean daily consumption of nutrients was calculated using an ad hoc computer program developed for the analysis of questionnaires, and the Chinese food composition table was used as a nutrient database ${ }^{19}$. The FFQ has been shown to be valid and reproducible as described in detail previously ${ }^{17}$. The Spearman correlation coefficients between FFQ and 4-day weighed dietary records (WDRs) were 0.66 for onion consumption, 0.49 for energy intake, and 0.35-0.54 for nutrients ( $\mathrm{n}-3$ fatty acid, fat, and carbohydrate). Spearman's rank correlation coefficients between two FFQs (collected approximately 3 months apart in a random sample of 150 participants) were 0.68 for energy intake, $0.62-0.79$ for food items (fruits, vegetables, sweet foods, and beverages), and 0.72 for onion.

Factor analysis with principal component based on the original 99 foods/food groups listed in the FFQ (onion and garlic were excluded in the calculation) was used to derive dietary patterns and to determine factor loadings for each food item (gram). Varimax rotation was applied to enhance interpretability. Three factors (sweet pattern, healthy pattern, and animal food pattern) were identified through combining criteria of the eigenvalues (greater than 1.0), scree plot test, and interpretability ${ }^{20}$.

Participants reported their frequency of onions consumption over the previous month by selecting the following options: almost never, < 1 time/week, 1 time/week, 2-3 times/week, 4-6 times/week, 1 time/day, and $\geq 2$ times/day. Based on the frequency distribution of responses, we summarized the categories of onions in quantile in the following way: $<1$ time/week, 1-3 times/week, 4-6 times/week, and $\geq 7$ times/week. 


\section{Definition of SCH}

Fasting blood samples were taken by venipuncture of the cubital vein in the morning after an 8 to 12 hour overnight fast. Chemiluminescence immunoassay was used to measure serum FT3, FT4, and TSH levels, using the ADVIA Centaur FT3, FT4, and TSH3-Ultra analyzer (Siemens Healthcare Diagnostics, New York, NY). The ranges of measurement for FT3, FT4, and TSH were 0.3-30.8 pmol/L, 1.3-155 pmol/L, and $0.001-150 \mathrm{mIU} / \mathrm{L}$, respectively. Based on the previous reports and national guidelines ${ }^{3,21}$, euthyroidism was defined with TSH values of between 0.55-4.78 mIU/L and FT4 between 11.5-22.7 pmol/L. SCH was diagnosed with TSH $>4.78 \mathrm{IU} / \mathrm{ml}$ and normal FT4 levels; and clinical hypothyroidism was considered when there were high TSH and low FT4 values (<11.50 pmol/L).

\section{Assessment of other variables}

The anthropometric measurements (including body height, body weight, and waist circumference (WC)) were measured by well-trained investigators using a standard protocol, and the body mass index (BMI) was computed as the body weight divided by body height squared $\left(\mathrm{kg} / \mathrm{m}^{2}\right)$. Levels of fasting blood glucose (FBG) were measured by glucose oxidase method. As for lipids, triglycerides (TG) and total cholesterol (TC) were measured by enzymatic methods. Low-density lipoprotein (LDL) was measured by the polyvinyl sulfuric acid precipitation method, and high-density lipoprotein (HDL) was measured by the chemical precipitation method using appropriate kits on a Cobas 8000 analyzer (Roche, Mannheim, Germany). Blood pressure (BP) was measured twice from the upper right arm using an automatic device (Andon, Tianjin, China) after 5 min of rest in a seated position. Hypertension was defined as systolic blood pressure (SBP) of $140 \mathrm{mmHg}$ and/or diastolic blood pressure (DBP) of $\geq 90 \mathrm{mmHg}$ or having history of hypertension.. Physical activity (PA) in the most recent week was assessed using the short form of the International Physical Activity Questionnaire (IPAQ) ${ }^{22}$, and estimated as metabolic equivalents in hours per week (MET-hour/week).

Information on age, gender, educational level, employment status, household income, smoking and alcohol consumption status, lifestyles were obtained from a questionnaire survey. A detailed personal and family history of physical illness (including CVD, hypertension, hyperlipidemia, and diabetes) and current medications was noted from "yes" or "no" responses to relevant questions. Depressive symptoms were evaluated by the Chinese version of the Zung Self-Rating Depression Scale.

\section{Statistical analysis}

All statistical analyses were performed using the Statistical Analysis System 9.3 edition for Windows (SAS Institute Inc., Gary, NC, USA). The log transformation for those non-normal distribution variables was applied before the statistical analysis. Analysis of covariance for continuous variables and logistic regression analysis for categorical variables were used to compare participant characteristics among different categories of onion consumption. The characteristics of the participants were presented as geometric mean and $95 \%$ confidence interval $(\mathrm{Cl})$ for continuous variables, or as percentage for categorical variables. Multiple logistic regression models were used to assess the association between 
onion intake and $\mathrm{SCH}$. The odds ratio (OR) and the corresponding $95 \% \mathrm{Cl}$ were calculated using the $<1$ time/week group as the reference. In model 2, we adjusted for age and BMI. In model 3, we additionally adjusted for smoking status, drinking status, educational level, working status, household income, PA, family history of disease, personal history of disease, total energy intake and three major dietary patterns (garlic and onion were not included in the calculation). In a final model, we further adjusted for all variables in model 3 and total garlic intake. Stratified analyses were performed to explore whether the association between onion consumption and prevalence of SCH differ by age ( $<40,40-60,>60$ years).

Furthermore, the multiple logistic regression models were used to examine the relationship between quantile of onion consumption and $\mathrm{SCH}$ with adjustment for the main covariates: age $(<40,40-60,>60$ years), sex (men or women), BMI ( $<24.0$ or $\geq 24.0 \mathrm{~kg} / \mathrm{m}^{2}$ ), smoking status (current, former, or never), alcohol drinking status (everyday drinker, sometime drinker, ex-drinker, or non-drinker), education level (< or $\geq$ college graduate), occupation (managers, professionals, or other), household income ( $\leq$ or $>10,000$ Yuan), physical activity (< or $\geq 23$ MET-hour/week), hypertension (yes or no), hyperlipidemia (yes or no), diabetes (yes or no), and depressive symptoms score ( $<$ or $\geq 45$ ). The interactions between the categories of onion consumption and $\mathrm{SCH}$ in female were tested through the addition of the cross-product terms to the regression models. All $P$ values for linear trends were calculated by using the categories of onions consumption ( $<1$ time/week: 1; 1-3 times/week: 2; 4-6 times/week: 3; and $\geq 7$ times/week: 4). All tests were two-tailed and $P<0.05$ was defined as statistically significant.

\section{Results}

In the present study, the prevalence of SCH was $4.6 \%(547 / 11,805)$. The mean age was $45.2 \pm 11.3$ years, ranging from 20 to 90 years, and 6515 participants (55.2\%) were men. Baseline characteristics of study participants according to $\mathrm{SCH}$ status are shown in Table 1. 
Table 1

Characteristics of participants $(n=11,805)$.

\begin{tabular}{|c|c|c|c|}
\hline Characteristics & All & Men & Women \\
\hline No. of participants & 11,805 & 6,515 & 5,290 \\
\hline Age (y) & $45.2(45.0,45.4)^{a}$ & $45.6(45.4,45.9)$ & $44.6(44.3,45.0)$ \\
\hline $\mathrm{BMI}\left(\mathrm{kg} / \mathrm{m}^{2}\right)$ & $24.9(24.9,25.0)$ & $26.1(26.0,26.2)$ & $23.5(23.4,23.6)$ \\
\hline WC (cm) & $84.4(84.2,84.6)$ & $89.9(89.7,90.2)$ & $77.6(77.3,77.8)$ \\
\hline $\mathrm{TC}(\mathrm{mmol} / \mathrm{L})$ & $4.88(4.87,4.90)$ & $4.92(4.90,4.94)$ & $4.84(4.81,4.86)$ \\
\hline $\mathrm{TG}(\mathrm{mmol} / \mathrm{L})$ & $1.51(1.48,1.53)$ & $1.79(1.76,1.83)$ & $1.15(1.13,1.17)$ \\
\hline LDL-C (mmol/L) & $2.88(2.87,2.89)$ & $2.95(2.93,2.97)$ & $2.79(2.77,2.81)$ \\
\hline $\mathrm{HDL}-\mathrm{C}(\mathrm{mmol} / \mathrm{L})$ & $1.36(1.35,1.37)$ & $1.22(1.21,1.22)$ & $1.54(1.53,1.55)$ \\
\hline $\mathrm{FBG}(\mathrm{mmol} / \mathrm{L})$ & $5.27(5.25,5.29)$ & $5.42(5.39,5.44)$ & $5.10(5.08,5.13)$ \\
\hline $\mathrm{SBP}(\mathrm{mmHg})$ & $\begin{array}{l}122.8(122.5 \\
123.1)\end{array}$ & $\begin{array}{l}126.3(125.9 \\
126.7)\end{array}$ & $\begin{array}{l}118.6(118.1 \\
119.0)\end{array}$ \\
\hline $\mathrm{DBP}(\mathrm{mmHg})$ & $77.9(77.7,78.1)$ & $81.5(81.2,81.8)$ & $73.5(73.2,73.8)$ \\
\hline SDS score & $36.4(36.2,36.5)$ & $36(35.8,36.2)$ & $36.8(36.6,37.0)$ \\
\hline PA (MET× hour/week) & $20.8(20.1,21.4)$ & $21.8(20.9,22.6)$ & $19.5(18.6,20.4)$ \\
\hline Total energy intake (kcal/day) & $\begin{array}{l}2161.4(2149.0, \\
2173.8)\end{array}$ & $\begin{array}{l}2257.2(2240.5 \\
2273.9)\end{array}$ & $\begin{array}{l}2043.3(2025.2 \\
2061.5)\end{array}$ \\
\hline $\begin{array}{l}\text { Sweet food dietary pattern } \\
\text { score }\end{array}$ & $0.00(-0.02,0.02)$ & $-0.16(-0.18,-0.13)$ & $0.20(0.17,0.22)$ \\
\hline Healthy dietary pattern score & $0.00(-0.02,0.02)$ & $0.23(0.20,0.25)$ & $-0.27(-0.30,0.25)$ \\
\hline $\begin{array}{l}\text { Animal food dietary pattern } \\
\text { score }\end{array}$ & $0.00(-0.02,0.02)$ & $0.11(0.08,0.13)$ & $-0.13(-0.16,-0.11)$ \\
\hline \multicolumn{4}{|l|}{ Smoking status (\%) } \\
\hline Current smoker & 22.2 & 38.5 & 1.83 \\
\hline Ex-smoker & 6.72 & 11.5 & 0.79 \\
\hline Non-smoker & 71.1 & 50.0 & 97.4 \\
\hline \multicolumn{4}{|l|}{ Alcohol drinking status (\%) } \\
\hline Everyday & 6.48 & 11.0 & 0.74 \\
\hline Sometime & 58.2 & 71.3 & 42.1 \\
\hline
\end{tabular}




\begin{tabular}{|c|c|c|c|}
\hline Characteristics & All & Men & Women \\
\hline Ex-drinker & 8.61 & 8.62 & 8.61 \\
\hline Non-drinker & 26.7 & 9.02 & 48.6 \\
\hline $\begin{array}{l}\text { Educational level ( } \geq \text { college } \\
\text { grade, \%) }\end{array}$ & 60.7 & 64.5 & 55.9 \\
\hline \multicolumn{4}{|l|}{ Occupation (\%) } \\
\hline Managers & 39.8 & 43.4 & 35.3 \\
\hline Professionals & 14.9 & 16.9 & 12.4 \\
\hline Other & 45.3 & 39.7 & 52.3 \\
\hline $\begin{array}{l}\text { Household income ( } \geq 10,000 \\
\text { Yuan, \%) }\end{array}$ & 45.6 & 49.0 & 41.4 \\
\hline Family history of diseases (\%) & 30.0 & 39.8 & 17.8 \\
\hline CVD & 33.6 & 32.5 & 35.0 \\
\hline Hypertension & 53.4 & 52.2 & 54.8 \\
\hline Hyperlipidemia & 0.19 & 0.20 & 0.19 \\
\hline Diabetes & 26.9 & 25.7 & 28.5 \\
\hline \multicolumn{4}{|c|}{$\begin{array}{l}\text { Abbreviations: BMI, body mass index; CVD, cardiovascular disease; DBP, diastolic blood pressure; FBG } \\
\text { fasting blood glucose; HDL-C, high-density lipoprotein cholesterol; LDL-C, low-density lipoprotein } \\
\text { cholesterol; MET, metabolic equivalent; SDS, Self-Rating Depression Scale; PA, physical activity; SBP, } \\
\text { systolic blood pressure; TC, total cholesterol; TG, triglycerides; WC, waist circumference. }\end{array}$} \\
\hline
\end{tabular}

Table 2 presents the associations between onion consumption categories and $\mathrm{SCH}$. The crude and adjusted relationship onion consumption and the prevalence of $\mathrm{SCH}$ were presented in Table 2. The crude ORs $(95 \% \mathrm{Cl})$ of $\mathrm{SCH}$ across categories of onion consumption were 1.00 (reference) for $<1$ time/week, $0.89(0.56,1.45)$ for $1-3$ times/week, $1.13(0.69,1.93)$ for $\geq 4-6$ times/week and $1.18(0.70,2.05)$ for $\geq 7$ times/week ( $P$ for trend $=0.50$ ) in men, 1.00 (reference) for $<1$ time/week, $0.87(0.65,1.16)$ for $1-3$ times/week, $0.71(0.52,0.96)$ for $\geq 4-6$ times/week and $0.66(0.48,0.91)$ for $\geq 7$ times/week $(P$ for trend $<0.01$ ) in women. In Model 2 we adjusted for age and BMI, in Model 3 further adjusted for sociodemographic characteristics, lifestyle factors, total energy intake, and the dietary quality (three major dietary patterns) these associations were not altered. The last model adjusted for total garlic and did not modify the findings. The fully adjusted ORs ( $95 \% \mathrm{Cls})$ for $\mathrm{SCH}$ across categories of onion consumption were 1.00 (reference) for $<1$ time/week, $1.16(0.69,2.01)$ for $1-3$ times/week, $1.27(0.75$, 2.23) for $4-6$ times/week, and $1.16(0.65,2.12)$ for $\geq 7$ times/week ( $P$ for trend $=0.60)$ in men, the corresponding ORs $(95 \% \mathrm{Cls})$ were 1.00 (reference), $0.99(0.74,1.34), 0.73(0.53,1.01)$ and $0.66(0.46$, 
0.95) ( $P$ for trend $<0.01)$ in women. Stratified analyses indicated that onion consumption was associated with $\mathrm{SCH}$ in younger women $(<45)$ but not in elder women $(>60)$ (Fig. 2). 
Table 2

Associations between frequency of onion consumption and risk of $\mathrm{SCH}(n=11,805)$.

\begin{tabular}{|c|c|c|c|c|c|}
\hline \multirow{2}{*}{$\begin{array}{l}\text { logistic regression } \\
\text { model }\end{array}$} & \multicolumn{4}{|c|}{ Frequency of onion consumption } & \multirow{2}{*}{$\begin{array}{l}P \text { for } \\
\text { trend }^{\text {a }}\end{array}$} \\
\hline & $\begin{array}{l}<1 \\
\text { time/week }\end{array}$ & $\begin{array}{l}1-3 \\
\text { times/week }\end{array}$ & $\begin{array}{l}4-6 \\
\text { times/week }\end{array}$ & 7times/week & \\
\hline No. of men & 902 & 2,132 & 1,983 & 1,498 & \\
\hline No. of SCH & 21 & 53 & 52 & 41 & \\
\hline Model $1^{b}$ & $\begin{array}{l}1.00 \\
\text { (reference) }\end{array}$ & $\begin{array}{l}1.07(0.65 \\
1.82)^{c}\end{array}$ & $\begin{array}{l}1.13(0.69 \\
1.93)\end{array}$ & $\begin{array}{l}1.18(0.70 \\
2.05)\end{array}$ & 0.50 \\
\hline Model $2^{d}$ & $\begin{array}{l}1.00 \\
\text { (reference) }\end{array}$ & $\begin{array}{l}1.16(0.70, \\
1.98)\end{array}$ & $\begin{array}{l}1.27(0.77 \\
2.17)\end{array}$ & $\begin{array}{l}1.26(0.74 \\
2.18)\end{array}$ & 0.38 \\
\hline Model $3^{\mathrm{e}}$ & $\begin{array}{l}1.00 \\
\text { (reference) }\end{array}$ & $\begin{array}{l}1.10(0.66, \\
1.89)\end{array}$ & $\begin{array}{l}1.19(0.71, \\
2.06)\end{array}$ & $\begin{array}{l}1.13(0.64 \\
2.03)\end{array}$ & 0.66 \\
\hline Model $4^{f}$ & $\begin{array}{l}1.00 \\
\text { (reference) }\end{array}$ & $\begin{array}{l}1.16(0.69 \\
2.01)\end{array}$ & $\begin{array}{l}1.27(0.75 \\
2.23)\end{array}$ & $\begin{array}{l}1.16(0.65 \\
2.12)\end{array}$ & 0.60 \\
\hline No. of women & 962 & 1,691 & 1,438 & 1,199 & \\
\hline No. of SCH & 85 & 131 & 92 & 72 & \\
\hline Model $1^{b}$ & $\begin{array}{l}1.00 \\
\text { (reference) }\end{array}$ & $\begin{array}{l}0.87(0.65 \\
1.16)\end{array}$ & $\begin{array}{l}0.71(0.51, \\
0.96)\end{array}$ & $\begin{array}{l}0.66(0.48 \\
0.91)\end{array}$ & $<0.01$ \\
\hline Model $2^{d}$ & $\begin{array}{l}1.00 \\
\text { (reference) }\end{array}$ & $\begin{array}{l}0.93(0.68, \\
1.28)\end{array}$ & $\begin{array}{l}0.72(0.52, \\
0.97)\end{array}$ & $\begin{array}{l}0.65(0.46 \\
0.90)\end{array}$ & $<0.01$ \\
\hline Model $3^{\mathrm{e}}$ & $\begin{array}{l}1.00 \\
\text { (reference) }\end{array}$ & $\begin{array}{l}0.96(0.71, \\
1.29)\end{array}$ & $\begin{array}{l}0.72(0.52, \\
0.99)\end{array}$ & $\begin{array}{l}0.66(0.46 \\
0.94)\end{array}$ & $<0.01$ \\
\hline Model $4^{f}$ & $\begin{array}{l}1.00 \\
\text { (reference) }\end{array}$ & $\begin{array}{l}0.99(0.73, \\
1.33)\end{array}$ & $\begin{array}{l}0.72(0.52, \\
0.99)\end{array}$ & $\begin{array}{l}0.65(0.45 \\
0.93)\end{array}$ & $<0.01$ \\
\hline \multicolumn{6}{|c|}{ Abbreviation: $\mathrm{SCH}$, subclinical hypothyroidism. } \\
\hline \multicolumn{6}{|c|}{ a Analysis by multiple logistic regression model. } \\
\hline \multicolumn{6}{|c|}{ b Model 1 was unadjusted model. } \\
\hline \multicolumn{6}{|c|}{ c Odds ratio ( $95 \%$ confidence interval) (all such values). } \\
\hline \multicolumn{6}{|c|}{${ }^{\mathrm{d}}$ Model 2 was adjusted for age and body mass index. } \\
\hline \multicolumn{6}{|c|}{$\begin{array}{l}\text { e Model } 3 \text { was additionally adjusted for smoking status, alcohol drinking status, education level, } \\
\text { occupation, household income, physical activity, family history of diseases (cardiovascular disease } \\
\text { and diabetes), individual history of diseases (hypertension, hyperlipidemia, and diabetes), Self-Rating } \\
\text { Depression Scale score, total energy intake, three main dietary pattern scores (onion and garlic intake } \\
\text { were not included in the calculation). }\end{array}$} \\
\hline
\end{tabular}




\begin{tabular}{|c|c|c|c|c|c|}
\hline \multirow{2}{*}{$\begin{array}{l}\text { logistic regression } \\
\text { model }\end{array}$} & \multicolumn{4}{|c|}{ Frequency of onion consumption } & \multirow{2}{*}{$\begin{array}{l}P \text { for } \\
\text { trend a }^{a}\end{array}$} \\
\hline & $\begin{array}{l}<1 \\
\text { time/week }\end{array}$ & $\begin{array}{l}1-3 \\
\text { times/week }\end{array}$ & $\begin{array}{l}4-6 \\
\text { times/week }\end{array}$ & $\underset{7 \text { times/week }}{\geq}$ & \\
\hline
\end{tabular}

All interactions were not statistically significant ( $P$ for interaction $>0.05)$, no significant interactions between onion consumption and $\mathrm{SCH}$ were observed in the final models in female.

\section{Discussion}

In this population-based study, we observed that dietary onion intake was significantly associated with a lower prevalence of $\mathrm{SCH}$ among women, but not men. To our knowledge, this was the first study to assess the association between onion consumption and $\mathrm{SCH}$ in such a large general population.

We adjusted for multiple potentially confounding factors in our analysis. First, since studies have shown that thyroid function is related to age ${ }^{23}$ and $\mathrm{BMI}^{24}$, we adjusted for these two variables. After adjustment for age and $\mathrm{BMI}$, a more obvious significantly relationship between onion consumption and $\mathrm{SCH}$ was observed. Secondly, since studies ${ }^{8,25}$ have shown that sociodemographic factors, lifestyle factors, nutritional status, and chronic diseases could also influence the prevalence of $\mathrm{SCH}$, we made further adjustments for smoking status, drinking status, educational level, working status, household income, PA, family history of disease, personal history of disease, three major dietary patterns (removing the onion) and total energy intake. However, adjustments for these confounding factors did not change the observed associations. Finally, we have adjusted garlic intake as it contains similar ingredients to onion ${ }^{10}$. After these adjustments, onion consumption has a more obvious correlation with $\mathrm{SCH}$ in women.

The present study shows that the prevalence of $\mathrm{SCH}$ is $4.63 \%$, which is similar to the previously reported $3 \%-15 \%$ among populations ${ }^{26}$. This study also showed that $\mathrm{SCH}$ occurs more frequently in women (2.56\% in men and $7.18 \%$ in women), it is consistent with previous study 27 .

Since sex-specific differences were observed in $\mathrm{SCH}$, we analyzed the relationship between onion consumption and $\mathrm{SCH}$ by sex in this study. We found a negative relationship between onion consumption and $\mathrm{SCH}$ in women but not in men. This result may be explained by the regulatory effect of estrogen on thyroid. Higher estrogen levels were shown to increase thyroid-binding globulin (TBG) levels, which could bind to circulating thyroid hormones, and subsequently decrease FT3 and FT4 concentrations ${ }^{28}$. However, that extracts from onions can influence aromatase production and enhance the estrogen steroid synthesis ${ }^{29}$. Further study is needed to determine the molecular mechanisms responsible.

It is worth noting that negatively relationship between raw onion consumption and hypothyroidism in younger individuals, but not in elderly (see Fig. 2). This phenomenon may be due to thyroid gland would undergo important functional changes during aging, the clinical course of thyroid diseases in elderly 
people differs from that observed in younger subjects. Studies have shown that TSH secretion in response to thyrotropin-releasing hormone (TRH) is reduced in aging individuals, and serum TSH level is usually lower in older than in young people in response to decreased thyroid hormone concentrations, suggesting a certain level of insensitivity of thyrotrophic cells in anterior pituitary, occurring with age; moreover, nocturnal surge of TSH is to various degree lost in the elderly ${ }^{30}$.

Although the exact mechanisms of onion consumption in decreasing SCH have not been elucidated, the substances contained in onions may be candidates for this negative relationship. On the one hand, organosulfur compounds, the major volatile constituent of common onion, has been shown to inhibit thyroid activity in rats. It is speculated that the consumption of volatile constituents of Allium species foods (onion, garlic, great-headed garlic, etc.) may contribute to the prevalence of thyroid diseases ${ }^{31}$. On the other hand, the trace element Se links onion and thyroid function. Ruz $\mathrm{M}$ et al. revealed total thyroid GPx activity was reduced through feeding rats on diets deficient in one or more of the trace elements $\mathrm{Se}^{32}$. Another study indicated that adequate $\mathrm{Se}$ is required for effective thyroid hormone synthesis after iodide supplementation ${ }^{33}$.

The major strengths of this study are it firstly assessed the relationship between onion consumption and $\mathrm{SCH}$ in a large-scale adult population from an iodine-replete area. Furthermore, we controlled for various potential confounders. Nonetheless, several biases and limitations should be considering in the present study. Firstly, a causal relationship cannot be determined since it is cross-sectional design. Secondly, although we adjusted for some potential confounding factors, there are still many unknown factors, which could influence relationship between onion consumption and $\mathrm{SCH}$. Thirdly, data on the cooking methods of onion were not available in this study. Thus, the probable unknown effects of different cooking and processing methods on onion. Finally, since the study results only represent the study region, it is possible that our results cannot be generalized to other populations.

\section{Conclusion}

In conclusion, the higher intake of onion was associated with a decreased prevalence $\mathrm{SCH}$ based on a large-scale adult population in women, but not men. Further prospective studies or clinical trials are needed to confirm the causality of the associations.

\section{Abbreviations}

FT3, Serum free triiodothyronine; FT4, free thyroxine; TSH, thyroid-stimulating hormone; $\mathrm{SCH}$, subclinical hypothyroidism; Se, selenium; SAC, Sallylcysteine; TCLSIH, Tianjin Chronic Low-grade Systemic Inflammation and Health; FFQ, Food Frequency Questionnaire; WDRs, weighed dietary records; WC, waist circumference; BMI, body mass index; FBG, fasting blood glucose; TG, triglycerides; TC, total cholesterol; LDL, low-density lipoprotein cholesterol; HDL, high-density lipoprotein cholesterol; BP, blood pressure; DBP, diastolic blood pressure; SBP, systolic blood pressure; PA, physical activity; IPAQ, International Physical Activity Questionnaire; $\mathrm{Cl}$, confidence interval; OR, odds ratio. 


\section{Declarations}

Acknowledgments: The authors gratefully acknowledge all the people that have made this study.

Authors' contributions: J.Z. and Y.G. analyzed data and wrote the paper. M.G., Q.Z., L.L., H.W., S.Z., Y.W., T.Z., X.W., X.Z., X.W., S.S., M.Z., Q.J. and K.S.conducted research. K.N. designed research and had primary responsibility for final content. All authors read and approved the final manuscript.

Conflict of interest: No author has a conflict of interest to disclose.

\section{References}

1. Asvold BO, Vatten LJ \& Bjoro T. Changes in the prevalence of hypothyroidism: the HUNT Study in Norway. Eur J Endocrinol 2013169 613-620.

2. Biondi B, Cappola AR \& Cooper DS. Subclinical Hypothyroidism. Jama 2019322153.

3. Chaker L, Bianco AC, Jonklaas J \& Peeters RP. Hypothyroidism. The Lancet 2017390 1550-1562.

4. Huber G, Staub JJ, Meier C, Mitrache C, Guglielmetti M, Huber P \& Braverman LE. Prospective study of the spontaneous course of subclinical hypothyroidism: prognostic value of thyrotropin, thyroid reserve, and thyroid antibodies. J Clin Endocrinol Metab 200287 3221-3226.

5. Garber JR, Cobin RH, Gharib H, Hennessey JV, Klein I, Mechanick JI, Pessah-Pollack R, Singer PA, Woeber KA, American Association of Clinical E \& American Thyroid Association Taskforce on Hypothyroidism in A. Clinical practice guidelines for hypothyroidism in adults: cosponsored by the American Association of Clinical Endocrinologists and the American Thyroid Association. Endocr Pract 201218 988-1028.

6. Effraimidis $\mathrm{G} \&$ Wiersinga WM. Mechanisms in endocrinology: autoimmune thyroid disease: old and new players. Eur J Endocrinol 2014170 R241-252.

7. Rayman MP. Multiple nutritional factors and thyroid disease, with particular reference to autoimmune thyroid disease. Proc Nutr Soc 201978 34-44.

8. Andrade GRG, Gorgulho B, Lotufo PA, Bensenor IM \& Marchioni DM. Dietary Selenium Intake and Subclinical Hypothyroidism: A Cross-Sectional Analysis of the ELSA-Brasil Study. Nutrients 201810.

9. Liang J, Zhao N, Zhu C, Ni X, Ko J, Huang H, Ma S, Udelsman R \& Zhang Y. Dietary patterns and thyroid cancer risk: a population-based case-control study. Am J Trans/ Res 2020 12 180-190.

10. Arnault I \& Auger J. Seleno-compounds in garlic and onion. J Chromatogr A 2006 1112 23-30.

11. Nicastro HL, Ross SA \& Milner JA. Garlic and onions: their cancer prevention properties. Cancer Prev Res (Phila) 20158 181-189.

12. Borek C. Antioxidant health effects of aged garlic extract. J Nutr 2001131 1010S-1015S.

13. Saravanan G \& Ponmurugan P. Antidiabetic effect of S-allylcysteine: effect on thyroid hormone and circulatory antioxidant system in experimental diabetic rats. J Diabetes Complications 201226 280285. 
14. Machackova J, Barta J \& Dhalla NS. Molecular defects in cardiac myofibrillar proteins due to thyroid hormone imbalance and diabetes. Canadian Journal of Physiology and Pharmacology 200583 1071-1091.

15. B H, H J \& M M. Effects of cell phone radiation on the levels of T3, T4 and TSH, and histological changes in thyroid gland in rats treated with Allium sativum extract. African Journal of Biotechnology 201413 163-169.

16. Schomburg L. Selenium, selenoproteins and the thyroid gland: interactions in health and disease. Nat Rev Endocrinol 20118 160-171.

17. Zhang S, Fu J, Zhang Q, Liu L, Meng G, Yao Z, Wu H, Bao X, Gu Y, Lu M, Sun S, Wang X, Zhou M, Jia Q, Song K, Xiang H, Wu Y \& Niu K. Association between nut consumption and non-alcoholic fatty liver disease in adults. Liver Int 201939 1732-1741.

18. Yu B YF, Su Q, Zhang Q, Liu L, Meng G, et al. A J-shaped association between soy food intake and depressive symptoms in Chinese adults. Clin Nutr 201837 1013-1018.

19. Yang Y WG, Pan X. China food composition. Beijing: Peking University Medical Press 2009.

20. Xia Y, Xiang Q, Gu Y, Jia S, Zhang Q, Liu L, Meng G, Wu H, Bao X, Yu B, Sun S, Wang X, Zhou M, Jia Q, Wu Y, Song K \& Niu K. A dietary pattern rich in animal organ, seafood and processed meat products is associated with newly diagnosed hyperuricaemia in Chinese adults: a propensity score-matched case-control study. Br J Nutr 2018119 1177-1184.

21. Gu Y, Zheng L, Zhang Q, Liu L, Meng G, Yao Z, Wu H, Xia Y, Bao X, Shi H, Wang H, Xu H, Sun S, Wang $X$, Zhou M, Jia Q, Song K \& Niu K. Relationship between thyroid function and elevated blood pressure in euthyroid adults. J Clin Hypertens (Greenwich) 201820 1541-1549.

22. Craig CL, Marshall AL, Sjöström M, Bauman AE, Booth ML, Ainsworth BE, Pratt M, Ekelund U, Yngve A, Sallis JF \& Oja P. International physical activity questionnaire: 12-country reliability and validity. Med Sci Sports Exerc 200335 1381-1395.

23. Gesing A, Lewiński A \& Karbownik-Lewińska M. The thyroid gland and the process of aging; what is new? Thyroid Res 2012516.

24. Abdi H, Kazemian E, Gharibzadeh S, Amouzegar A, Mehran L, Tohidi M, Rashvandi Z \& Azizi F. Association between Thyroid Function and Body Mass Index: A 10-Year Follow-Up. Ann Nutr Metab $201770338-345$.

25. Wu Q, Rayman MP, Lv H, Schomburg L, Cui B, Gao C, Chen P, Zhuang G, Zhang Z, Peng X, Li H, Zhao Y, He X, Zeng G, Qin F, Hou P \& Shi B. Low Population Selenium Status Is Associated With Increased Prevalence of Thyroid Disease. J Clin Endocrinol Metab 2015100 4037-4047.

26. Peeters RP. Subclinical Hypothyroidism. N Engl J Med 2017376 2556-2565.

27. Jiang L, Du J, Wu W, Fang J, Wang J \& Ding J. Sex differences in subclinical hypothyroidism and associations with metabolic risk factors: a health examination-based study in mainland China. $B M C$ Endocr Disord 202020100.

28. Arafah BM. Increased Need for Thyroxine in Women with Hypothyroidism during Estrogen Therapy. New England Journal of Medicine 2001344 1743-1749. 
29. Lee YH, Yang H, Lee SR, Kwon SW, Hong EJ \& Lee HW. Welsh Onion Root (Allium fistulosum) Restores Ovarian Functions from Letrozole Induced-Polycystic Ovary Syndrome. Nutrients 201810.

30. Lewiński A SE, Karbownik M. Aging processes and the thyroid gland. InAging and Age-Related Diseases: The Basics 2006 131-172.

31. Cowan JW, Saghir AR \& Salji JP. Antithyroid activity of onion volatiles. Aust J Biol Sci 196720 683685.

32. Ruz M, Codoceo J, Galgani J, Muñoz L, Gras N, Muzzo S, Leiva L \& Bosco C. Single and multiple selenium-zinc-iodine deficiencies affect rat thyroid metabolism and ultrastructure. J Nutr 1999129 174-180.

33. Zimmermann MB \& Köhrle J. The impact of iron and selenium deficiencies on iodine and thyroid metabolism: biochemistry and relevance to public health. Thyroid 200212 867-878.

\section{Figures}


Participants who had received health examinations $(\mathrm{n}=13,234)$

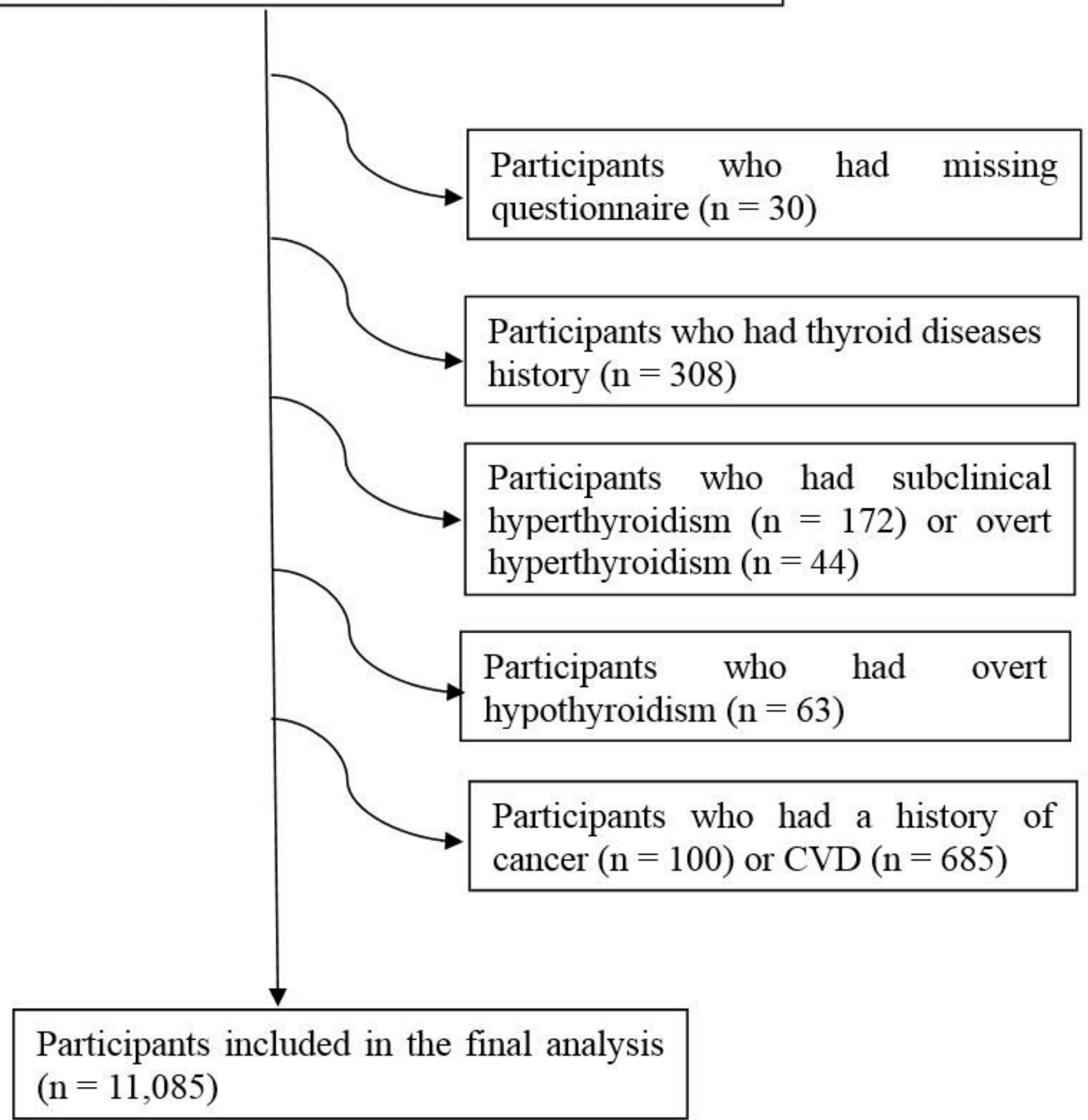

Figure 1

Flow diagram of study participant selection 


\section{onion consumption}

$<1$ time/week

1-3 times/week

4-6 times/week

$\geq 7$ times/week

\section{HR (95\% CI)}

1.00 (reference)

$0.61(0.36,1.40)$

$0.48(0.26,0.87)$

$0.43(0.20,0.87)$

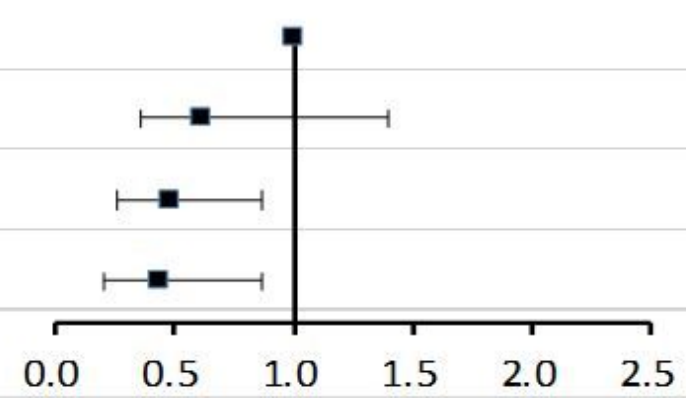

\section{0-60}

\section{onion cons umption}

$<1$ time/week

1-3 times/week

4-6 times/week

$\geq 7$ times/week

\section{HR $(95 \%$ CI)}

1.00 (reference)

$1.39(0.93,2.08)$

$0.81(0.52,1.26)$

$0.72(0.44,1.16)$

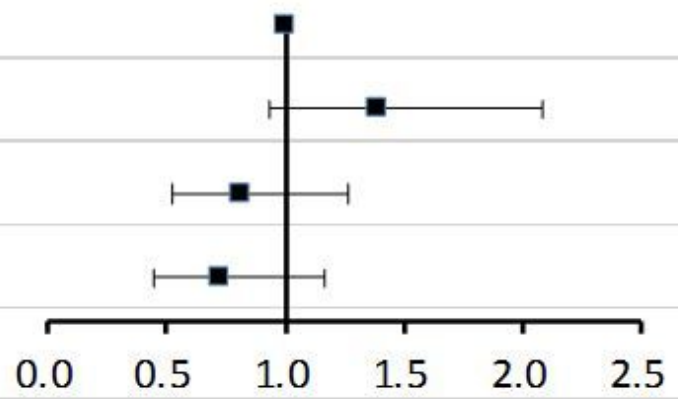

$>60$

\section{onion consumption}

$<1$ time/week

1-3 times/week

4-6 times/week

$\geq 7$ times/week

\section{HR (95\% CI)}

\subsection{0 (reference)}

$0.77(0.36,1.64)$

$1.01(0.50,2.06)$

$1.05(0.49,2.28)$

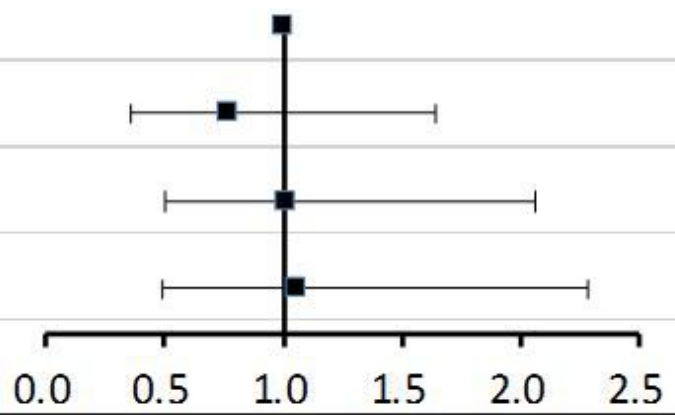

Figure 2

Association of seaweed consumption with SCH stratified by age in female. Multivariable model was adjusted for age, sex, BMI, smoking status, alcohol drinking status, education level, occupation, household income, physical activity, family history of disease (including cardiovascular disease, hypertension, hyperlipidemia, and diabetes), physical activity (continuous: MET-hour/week), SDS score (< or $\geq 45$ ), total energy intake, and three main dietary pattern scores. 